\title{
ALTERNATIF PENGGUNAAN PLASTIK POLYPROPYLENE PADA CAMPURAN ASPAL
}

\author{
Samsul Arif \\ Dosen Program Studi Teknik Sipil Universitas Islam Lamongan \\ email : samsularif90an@gmail.com
}

\begin{abstract}
Asphalt is a thermoplastic material that will become harder or thicker if the temperature is reduced and will be soft or more liquid if the temperature increases. As developments in asphalt mixtures, several studies have developed the use of plastic waste in an effort to reduce plastic waste that is difficult to recycle. In this research used type of PP plastic (Polypropylene) as alternative of asphalt mixture. the results of the study showed the lowest stability value that is on the normal laston of $1136 \mathrm{~kg}$, but the value still meets the specification of Bina Marga> 800kg. The lowest flow is on the normal laston of 3.62, the value still meets the provisions of Bina Marga > 3. The lowest Marshall Quotient value on the normal 307, is still meets the requirements of Bina Marga > 250. With the addition of PP plastic (Polypropylene) 2\% and 4\% showed better results than normal asphalt. Judging from the stability, flow and $M Q$ values, they are better than the normal asphalt.
\end{abstract}

Keywords: Asphalt, Marshall test, Stability, Flow, Marshall Quotient

\section{PENDAHULUAN}

Aspal adalah material thermoplastis yang akan menjadi keras atau lebih kental jika temperatur berkurang dan akan lunak atau lebih cair jika temperature bertambah. Sifat ini dinamakan kepekaan terhadap perubahan temperatur, yang dipengaruhi oleh komposisi kimiawi aspal walaupun mungkin mempunyai nilai penetrasi atau viskositas yang sama pada temperatur tertentu. Bersama dengan agregat, aspal merupakan material pembentuk campuran perkerasan jalan(Sukirman, 2007).

Lapis Aspal Beton (Laston) adalah suatu lapisan pada konstruksi jalan raya, yang terdiri dari campuran aspal keras dan agregat yang bergradasi menerus, dicampur, dihampar dan dipadatkan dalam keadaan panas pada suhu tertentu. Pembuatan laston dimaksudkan untuk mendapatkan suatu lapisan permukaan atau lapis antara pada perkerasan jalan raya yang mampu memberikan sumbangan daya dukung yang terukur serta berfungsi sebagai lapisan kedap air yang dapat melindungi konstruksi dibawahnya (Balitbang PU, 1989).

Seiring perkembangan dalam campuran aspal, beberapa penelitian telah mengembangkan penggunaan limbah plastik sebagai upaya mengurangi sampah plastik yang sulit didaur ulang. Secara garis besar terdapat dua macam plastik, yaitu resin termoplastik dan resin termoset. Resin termoplastik mempunyai sifat dapat diubah bentuknya jika dipanaskan, sedangkan resin termoset hanya dapat dibentuk satu kali saja. Beberapa nama plastik yang umum digunakan adalah HDPE (High Density Polyethylene), LDPE (Low Density Polyethylene), PP (Polypropylene), PVC (Polyvinyl chloride), PS (Polystryrene), dan PC (Polycarbonate). PE (Polyethylene) dan PP mempunyai banyak kesamaan dan sering disebut sebagai polyolefin. Untuk mempermudah proses daur ulang plastik, telah disetujui pemberian kode plastik secara internasional. Kode tersebut terutama digunakan pada kemasan plastik yang disposable atau sekali pakai. (http://ik.pom.go.id diakses pada tanggal 21 Agustus 2017).

Dalam penelitian ini digunakan jenis plastik PP (Polypropylene) sebagai alternatif campuran aspal. Karakteristik plastik PP (Polypropylene), adalah sebagai berikut: 


Ciri-ciri plastik jenis ini
biasanya transparan tetapi tidak
jernih atau berawan, keras tetapi
fleksibel, kuat, permukaan
berlilin, tahan terhadap bahan
kimia, panas dan minyak,
melunak pada suhu 140oC.

Tujuan penelitian yaitu untuk mengetahui kadar aspal optimum campuran aspal dengan penambahan plastik jenis PP (Polypropylene).

\section{METODE PENELITIAN Tahap Persiapan}

Tahap persiapan merupakan rangkaian kegiatan sebelum memulai pengumpulan data dan pengolahannya. Semua bahan yang digunakan pada penelitian ini mengacu pada spesifikasi umum yang dikeluarkan oleh Direktorat Jenderal Bina Marga tahun 2010 Revisi I.

\section{Pemeriksaan Aspal}

Pemeriksaan Aspal, meliputi:

1. Berat Jenis Aspal

2. Titik Lembek

3. Titik Nyala dan Titik Bakar

\section{Pemeriksaan Agregat}

1. Pemeriksaan Gradasi Agregat

2. Pemeriksaan Berat Jenis dan Penyerapan Agregat Kasar

3. Pemeriksaan Berat Jenis dan Penyerapan Agregat Halus

4. Penentuan Berat Isi Agregat

\section{Langkah Kerja Metode Marshall}

Langkah-langkah kerja campuran metode Marshall (Sukirman, 2007) adalah :

a. Mempelajari spesifikasi gradasi agregat campuran yang diinginkan dari spesifikasi campuran pekerjaan.

b. Merancang proporsi dari masing-masing agregat yang tersedia untuk mendapatkan agregat campuran dengan gradasi sesuai butir

c. Menentukan kadar aspal total dalam campuran

d. Membuat benda uji atau briket beton aspal

e. Melakukan uji Marshall untuk mendapatkan stabilitas dan kelelehan (flow) benda uji

f. Menghitung parameter Marshall yaitu VIM, VMA, VFA, berat volume campuran, dan parameter lain sesuai parameter yang ada pada spesifikasi campuran.

g. Menggambarkan hubungan antara kadar aspal dan parameter Marshall, setelah itu didapat nilai kadar aspal optimum.

h. Membuat Job Mix Formula.

\section{Prosedur Marshall untuk Campuran}

Prosedur pengujian ini digunakan dalam desain dan evaluasi untuk campuran perkerasan aspal. Ada dua ciri utama dalam metode percobaan Marshall untuk campuran aspal yakni, stabilitas dan flow test. Stabilitas dari campuran ditentukan sebagai suatu beban maksimum yang diperoleh melalui pembebanan benda uji pada temperatur standar saat dilakukan test yaitu $60^{\circ} \mathrm{C}$. Kelelehan plastis (flow) diukur sebagai suatu perubahan bentuk dalam satuan $0.1 \mathrm{~mm}$. Dalam percobaan ini usaha yang dilakukan adalah untuk mendapatkan Kadar Aspal Optimum pada tipe campuran agregat.

Benda uji yang kita buat ditimbang dan direndam dalam air selama 1 jam, selanjutnya dikeluarkan dan ditimbang lagi dalam keadaan kering permukaan jenuh. Kemudian benda uji direndam dalam bak perendam pada suhu $60^{\circ}$ C selama 30 menit.

Pengujian Marshall dilakukan dalam waktu tidak lebih dari 30 detik sejak diambil dari waterbath. Pembacaan untuk stabilitas dilakukan pada pembebanan tertinggi dalam $\mathrm{kg}$ pada arloji dan flow dicatat pada pembebanan puncak tersebut dalam satuan $0.1 \mathrm{~mm}$. Jika tinggi benda uji tidak persis sama dengan 63,5 $\mathrm{mm}$, maka hasil pembacaan arloji harus dikalikan dengan suatu faktor koreksi benda uji, sementara pembacaan arloji stabilitas juga harus dikalikan dengan angka koreksi proving ring. Dari hasil penimbangan benda uji sebelum dilakukan pembebanan dapat dihitung persen rongga dalam campuran, dan persen rongga terisi aspal.

\section{HASIL DAN PEMBAHASAN \\ Hasil Pemeriksaan Berat Jenis Dan Penyerapan Agregat Kasar}

Tabel 2 Hasil Pengujian Agregat Kasar

\begin{tabular}{lc}
\hline \multicolumn{1}{c}{ Satuan } & Besaran \\
\hline Bk(berat kering oven(gram) & 3522 \\
\hline $\begin{array}{l}\text { Bj(berat kering permukaan } \\
\text { jenuh(gram) }\end{array}$ & 3588,5 \\
\hline
\end{tabular}




\begin{tabular}{ll}
\hline $\mathrm{Ba}($ berat benda uji dalam air(gram) & 2213,5 \\
\hline (bulk specific gravity) $=\frac{b k}{b j-b a}$ & $=2,56$ \\
\hline (saturated surface gravity) $=\frac{b j}{b j-b a}$ & $=2,60$ \\
\hline (app.specific gravity) $=\frac{b k}{b k-b a}$ & $=2,68$ \\
\hline Penyerapan $=\frac{b j-b k}{b k} \times 100 \%$ & $=1,88 \%$
\end{tabular}

\section{Sumber : Hasil penelitian}

Dari perhitungan diketahui nilai berat jenis agregat kasar sudah memenuhi spesifikasi bina marga yaitu min 2,5 dan prosentase penyerapan maks 3\%. Berat jenis bulk, SSD dan berat jenis semu sebesar 2,56; 2,60; dan 2,68 . Sedangkan prosentase penyerapan sebesar $1,88 \%$.

\section{Hasil Pengujian Agregat Halus}

Tabel 4 Hasil Pengujian Agregat Halus

\begin{tabular}{lc}
\hline \multicolumn{1}{c}{ Satuan } & Besaran \\
\hline $\begin{array}{l}\text { Bk (berat sampel oven } \\
\text { kering(gram)) }\end{array}$ & 492,3 \\
\hline B(berat labu+air(gram)) & 630,2 \\
\hline $\begin{array}{ll}\text { Bt(berat piknometer+benda uji } \\
\text { SSD+air(gram)) }\end{array}$ & 941,4 \\
\hline (bulk specific gravity) $=\frac{\boldsymbol{b} \boldsymbol{k}}{\boldsymbol{b}+\mathbf{5 0 0}-\boldsymbol{b t}}$ & $=2,57$ \\
\hline (saturated surface gravity) & $=2,63$ \\
\hline (app. specific gravity) $=\frac{\boldsymbol{b} \boldsymbol{k}}{\boldsymbol{b}+\boldsymbol{b} \boldsymbol{k}-\boldsymbol{b} \boldsymbol{t}}$ & $=2,70$
\end{tabular}

$\begin{array}{ll}\text { Penyerapan }=\frac{(\mathbf{5 0 0}-\boldsymbol{A}) \boldsymbol{X 1 0 0}}{\boldsymbol{A}} & =1,91 \\ \text { Sumber }: \text { Hasil penelitian } & \end{array}$

Dari perhitungan diketahui nilai berat jenis agregat halus sudah memenuhi spesifikasi bina marga yaitu $\min 2,5$ dan prosentase penyerapan maks 3\%. Berat jenis bulk, SSD dan berat jenis semu sebesar 2,57; 2,63; dan 2,70. Sedangkan prosentase penyerapan sebesar $1,91 \%$.

\section{Pemeriksaan Aspal}

Pemeriksaan Titik Nyala Dan Titik Bakar Aspal

Tabel 5 Uji Titik Nyala dan Bakar Aspal

\begin{tabular}{cccc}
\hline $\begin{array}{c}{ }^{\mathbf{O}} \mathrm{C} \\
\text { dibawah } \\
\text { titik nyala }\end{array}$ & $\begin{array}{c}\text { Waktu( } \\
\text { menit) }\end{array}$ & ${ }^{\circ} \mathrm{C}$ & $\begin{array}{c}\text { Titik } \\
\text { nyala/titik } \\
\text { bakar }\end{array}$ \\
\hline 96 & 5 & 100 & \\
\hline 89 & 10 & 142 & \\
\hline
\end{tabular}

\begin{tabular}{ccc}
\hline 84 & 15 & 160 \\
\hline 77 & 20 & 170 \\
\hline 72 & 25 & 180 \\
\hline 69 & 30 & 182 \\
\hline 62 & 35 & 190 \\
\hline 56 & 40 & 160 \\
\hline 51 & 45 & 180 \\
\hline 46 & 50 & 200 \\
\hline 41 & 55 & 210 \\
\hline 36 & 60 & 226 \\
\hline 31 & 65 & 244 \\
\hline 26 & 70 & 258 \\
\hline 21 & 75 & 270 \\
\hline 16 & 80 & 282 \\
\hline 11 & 85 & 290 \\
\hline 6 & 90 & 308 \\
\hline 1 & 95 & 323 \\
\hline
\end{tabular}

Sumber: Hasil penelitian

Dari tabel diatas diketahui titik nyala aspal mencapai suhu $290^{\circ} \mathrm{C}$ dan mencapai titik bakar pada suhu $323^{\circ} \mathrm{C}$.

\section{Pemeriksaan Penetrasi Aspal}

Tabel 6 Penetrasi Aspal Pen 60/70

\begin{tabular}{|c|c|c|c|c|c|}
\hline \multirow{2}{*}{$\begin{array}{l}\text { Penetrasi } \\
25^{\circ} \mathrm{C} 100 \\
\text { gram,5 detik }\end{array}$} & \multicolumn{5}{|c|}{ Sampel } \\
\hline & I & II & III & IV & $\mathrm{V}$ \\
\hline \multirow[t]{3}{*}{ Pengamatan } & 70 & 62 & 72 & 71 & 70 \\
\hline & 64 & 73 & 68 & 74 & 67 \\
\hline & 66 & 66 & 67 & 67 & 69 \\
\hline Rata-rata & 66 & 67 & 69 & 70 & 68 \\
\hline
\end{tabular}

Hasil pengujian penetrasi aspal yaitu berturutturut sebesar 66, 67, 69, 70, 68. Nilai tersebut sudah memenuhi standar aspal yaitu 60/70 pen.

\section{Komposisi campuran aspal AC-WC}

Pembuatan rancangan campur (mix design) perencanaan campuran meliputi perencanaan gradasi agregat, penentuan kadar aspal dan pengukuran masingmasing fraksi baik agregat dan aspal.

Tabel 7 Komposisi bahan

\begin{tabular}{lll}
\hline No & Material & Komposisi \\
\hline 1 & Agregat kasar & $25 \%$ \\
\hline 2 & Agregat medium & $36 \%$ \\
\hline 3 & Agregat halus & $39 \%$ \\
\hline 4 & Aspal & $5 \%$ \\
\hline \multicolumn{2}{l}{ Sumber : Hasil Penelitian }
\end{tabular}


Kadar aspal 5\%

Tabel 8 Hasil Pengujian Marshall

Jumlah tumbukan $75 \times 2$

\begin{tabular}{ccccccccc}
\hline Benda Uji & $\begin{array}{c}\text { Berat } \\
\text { kering }\end{array}$ & $\begin{array}{c}\text { Berat } \\
\text { dalam air }\end{array}$ & SSD & $\begin{array}{c}\text { Densitas } \\
\text { gr/cc }\end{array}$ & $\begin{array}{c}\text { Pembacaan } \\
\text { dial }\end{array}$ & $\begin{array}{c}\text { Stabilitas } \\
\text { (kg) }\end{array}$ & $\begin{array}{c}\text { Flow } \\
(\mathbf{m m})\end{array}$ & $\begin{array}{c}\text { MQ } \\
(\mathbf{k g} / \mathbf{m m})\end{array}$ \\
\hline $0 \%$ & 1161 & 714 & 1191 & 2,43 & 279 & 1059 & 3,8 & 270 \\
\hline $0 \%$ & 1172 & 727 & 1207 & 2,44 & 294 & 1106 & 3,7 & 292 \\
\hline $0 \%$ & 1181 & 738 & 1223 & 2,43 & 333 & 1243 & 3,4 & 360 \\
\hline Rata-rata & 1171,3 & 726,3 & 1207 & 2,43 & 302 & 1136 & 3,62 & 307,3 \\
\hline PP 2\% & 1120 & 687 & 1150 & 2,41 & 364 & 1427 & 3,7 & 361 \\
\hline PP 2\% & 1130 & 692 & 1153 & 2,45 & 431 & 1677 & 4 & 396 \\
\hline PP 2\% & 1123 & 689 & 1150 & 2,43 & 378 & 1479 & 3,8 & 365 \\
\hline Rata-rata & 1124,3 & 689,3 & 1151 & 2,43 & 391 & 1527,6 & 3,83 & 374 \\
\hline PP 4\% & 1152 & 711 & 1183 & 2,44 & 445 & 1701 & 4,1 & 399 \\
\hline PP 4\% & 1149 & 700 & 1172 & 2,43 & 395 & 1514 & 3,6 & 403 \\
\hline PP 4\% & 1150 & 705 & 1176 & 2,44 & 425 & 1628 & 3,8 & 411 \\
\hline Rata-rata & 1150,3 & 705,3 & 1177 & 2,43 & 421,6 & 1614,3 & 3,83 & 404,3 \\
\hline
\end{tabular}

Sumber: Hasil Penelitian

\section{Parameter Pengujian Marshall}

Sifat-sifat campuran beraspal dapat dilihat dari parameter-parameter pengujian marshall antara lain :

\section{A.Stabilitas Marshall}

Nilai stabilitas diperoleh berdasarkan nilai masing-masing yang ditunjukkan oleh jarum dial. Stabilitas merupakan merupakan yang menunjukkan batas maksimum beban diterima oleh suatu campuran beraspal saat terjadi keruntuhan. Nilai stabilitas yang terlalu tinggi akan menghasilkan perkerasan yang terlalu kaku sehingga tingkat keawetannya berkurang.

Dari hasil pengujian marshall diketahui nilai stabilitas pada Laston normal (0\%) sebesar $1136 \quad \mathrm{~kg}$ sedangkan dengan penambahan plastik PP (Polypropylene) sebesar $1527 \mathrm{~kg}$. Nilai stabilitas tertinggi yaitu pada penambahan plastik PP (Polypropylene) 4\% yaitu sebesar $1614 \mathrm{~kg}$.

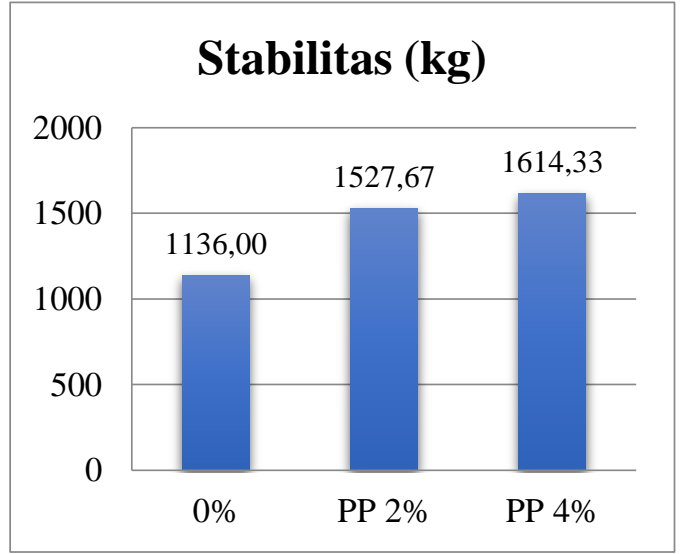

Gambar 1 Stabilitas (kg)

\section{B. Kelelehan (Flow)}

Seperti halnya cara memperoleh nilai stabilitas, nilai flow merupakan nilai dari masing-masing yang ditunjukkan oleh jarum dial (dalam satuan $\mathrm{mm}$ ). Suatu campuran yang memiliki kelelehan yang rendah akan lebih kaku dan cenderung untuk mengalami retak dini pada usia pelayanannya.

Pada tabel 8 diketahui nilai flow pada laston normal sebesar 3,62 sedangkan pada campuran laston dengan penambahan plastik PP (Polypropylene) 2\% dan 4\% menujukkan rata-rata nilai flow sebesar 3,83 . 


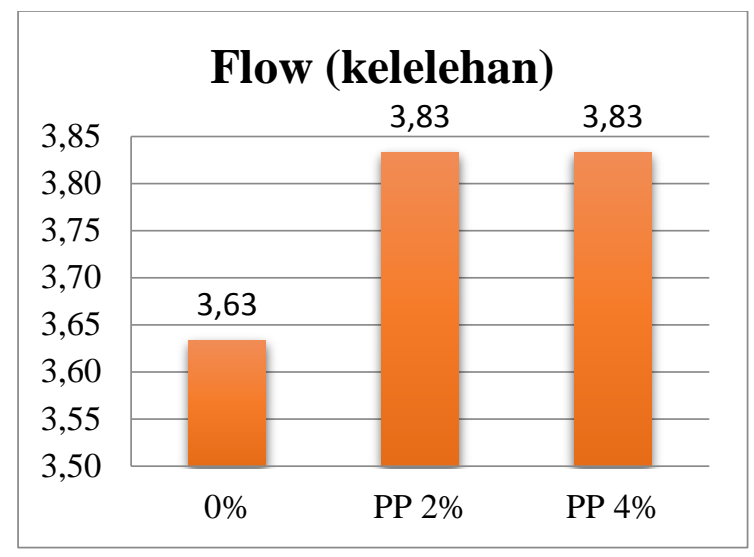

Gambar 2 Flow (kelelehan)

\section{Hasil Bagi Marshall (Marshall Quotient)}

Hasil bagi Marshall merupakan hasil bagi stabilitas dengan kelelehan (flow). Semakin tinggi MQ, maka akan semakin tinggi kekakuan suatu campuran dan semakin rentan campuran tersebut terhadap keretakan.

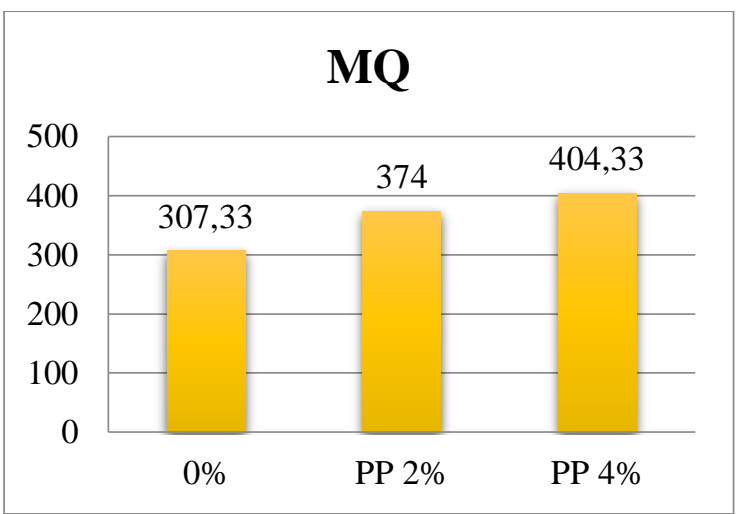

Gambar 3 Marshall Quotient

Dari gambar diatas terlihat nilai MQ terbesar yaitu pada PP 4\% yaitu sebesar 404 . Sedangkan nilai MQ terkecil yaitu pada laston normal (0\%) sebesar 307.

\section{KESIMPULAN}

Dari hasil penelitian didapat kesimpulan sebagai berikut:

a. Nilai stabilitas terendah yaitu pada Laston normal sebesar $1136 \mathrm{~kg}$, tetapi nilai tersebut masih memenuhi spesifikasi Bina Marga $>800 \mathrm{~kg}$.

b. Kelelehan (flow) terendah yaitu pada Laston normal sebesar 3,62, nilai tersebut masih memenuhi ketentuan dari Bina Marga $>3$.

c. Nilai Marshall Quotient terendah pada laston normal yaitu 307, nilai tersebut masih memenuhi ketentuan dari Bina Marga $>250$.

d. Dengan penambahan plastik PP (Polypropylene) 2\% dan 4\% menujukkan hasil yang lebih baik dari laston normal. Dilihat dari nilai stabilitas, flow dan MQ, kesemuanya lebih baik dari laston normal.

\section{DAFTAR PUSTAKA}

Ali H., 2011 Karakteristik Campuran Asphalt Concrete-Wearing Course(ACWC)Dengan Penggunaan Abu Vulkanik Dan Abu Batu Bara Sebagai Filler, Jurnal Fakultas Teknik Universitas Lampung.Lampung

ASTM C150 2007 Standart Specification For PortlandCementCement.copyright@int ernational united state

$\begin{array}{llll}\text { AASHTO } & 1990 \quad .15 & \text { Edtion.Standart }\end{array}$ Specification For Transportation Material And Methods of Sampling And Testing. Part II, Washington.USA

Anonim,2010, Spesifikasi Umum. Direktorat bina marga. Jakarta.

Anonim,1987 Spesifikasi Umum. Dinas Pekerjaan Umum direktorat jenderal bina marga. Jakarta

Anonim2015 Panduan Praktikum Perkerasan Jalan Raya. Teknik Sipil. Universitas Islam Lamongan 
Halaman ini sengaja dikosongkan 